\title{
COOPERATIVISMO: A ESCOLHA PELO COLETIVO
}

\author{
Nelsa Inês Fabian Nespolo ${ }^{1}$ \\ Cooperativa Central Justa Trama \\ e-mail
}

\begin{abstract}
Resumo
O texto aborda a iniciativas de ações do cooperativismo, suas práticas e contradições. Aponta o surgimento de outras formas de organização coletiva, definida como economia social e solidaria, com um resgate forte de princípios de coletividade e de democracia interna, e especialmente para enfrentar as diversas situações de desemprego e sobretudo de falta de perspectivas postos de trabalho.
\end{abstract}

Palavras-chave: Cooperativismo; Economia solidária, Organização Coletiva.

\section{COOPERATIVISM: THE CHOICE FOR THE COLLECTIVE}

\begin{abstract}
The text addresses initiatives of cooperative actions, their practices and contradictions. It points to the emergence of other forms of collective organization, defined as social and solidarity economy, with a strong recovery of collective principles and internal democracy, and especially to face the various situations of unemployment and especially lack of job prospects.
\end{abstract}

Keywords: Cooperatives; Solidarity Economy; Collective Organization.

${ }^{1}$ Costureira; Diretora presidente da Cooperativa Univens; Cooperativa Central Justa Trama, Vice-presidente da Unisol Brasil. Autora do livro Tramando Certezas e Esperanças, 2014.

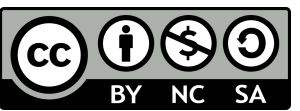

P2P \& INOVAÇÃO, Rio de Janeiro, v. 5 n. 1, Ed. Especial, p.1U/-1 13, 2018. 


\section{INTRODUÇÃO}

Vivemos em uma sociedade de contradições, portanto acompanhada de todas as desigualdades possíveis. Sempre houve e haverá os inconformados pelas injustiças sociais, e, sobretudo com as mazelas de pobreza e miséria gerada pelo sistema capitalista que vivemos. Neste contexto surgem iniciativas de ações, sobretudo econômicas de inconformidade de vender seu maior bem: a sua mão de obra, e vem o cooperativismo e no final do século passado a Economia solidaria. As tantas contradições de práticas do cooperativismo cooptadas pelo sistema capitalista provocam o surgimento de outras formas de organização coletiva, que definimos como economia social e solidaria, essas práticas se dão de forma vertical e horizontal.

As cooperativas de fachada que se proliferaram em todo mundo, se contrapõem as verdadeiras cooperativas autogestionárias. Ou seja, enquanto cooperativas sérias, convivem com processos de autogestão, democracia direta e distribuição justa dos ganhos entre os cooperados, as de fachada tem dono, os cooperados vendem sua mão de obra, portanto não se comercializa produto gerado ou serviço gerado, além disso o ganho e a riqueza gerada se concentra em quem administra a cooperativa. Isso criou um descrédito ao sistema cooperativista, pois as práticas se assemelham a empresas capitalista porem pioradas pois não respeitam os direitos conquistados pelos trabalhadores de carteira assinada (assalariados) com isso definimo-las como coopergatos porque são a precarização de mão de obra. Sem contar que as cooperativas vêm carregadas de legislações de seus países e em muitos casos dificultam o surgimento pelo excesso de burocracia, e outras exigências como o número de cooperados para ser reconhecida até 2012 eram no mínimo 20 associados(as) no Brasil. Atualmente com a alteração da lei das cooperativas de trabalho 7 pessoas fundam uma cooperativa no Brasil.

A cooperativa de trabalho pode ser:

a) cooperativa de produção: quando constituída por sócios que contribuem com trabalho para a produção em comum de bens e a cooperativa detém, a qualquer título, os meios de produção; ou

b) cooperativa de serviço: quando constituída por sócios para a prestação de serviços especializados a terceiros, sem a presença dos pressupostos da relação de emprego (Art. $4^{\circ}, \mathrm{I}$ e II). Essas cooperativas podem ser constituídas com o número mínimo de 07 (sete) sócios, mas não podem ser utilizadas para intermediação de mão de obra subordinada (Arts. $5^{\circ}$ e $6^{\circ}$ ). Isto não significa, entretanto, que as atividades das cooperativas, não possam ser realizadas no estabelecimento do contratante. 
A cooperativa de trabalho constituída por até 19 (dezenove) sócios poderá estabelecer, em Estatuto Social, composição para o conselho fiscal distinta da prevista no art. 56 da Lei $\mathrm{n}^{\circ}$ 5.764/71 (Lei n. 12.690/12).

Assim chega a Economia social e solidaria, com um resgate forte de princípios de coletividade e de democracia interna, e especialmente para enfrentar as diversas situações de desemprego e sobretudo de falta de perspectivas postos de trabalho. Ao mesmo tempo e com uma situação bem adversa do ponto de vista da economia dos países, a forma como a economia solidária se organiza no Brasil, na América Latina não é a mesma forma em que a Economia social se organiza na Europa. Um grito para enfrentar o desemprego gerado pelas empresas capitalistas, surgem as empresas recuperadas. Perguntamo-nos será que algum capitalista desistiria de sua empresa se esta tivesse viabilidade ou mercado? Assim as empresas recuperadas onde grande parte o capitalista dono anterior sugou a infraestrutura (prédio, instalações elétricas e hidráulicas), gerou dividas, quebrou a credibilidade do mercado tanto na venda como na compra de matéria prima e insumos, os trabalhadores que até a pouco só cumpriam ordens passam a ser donos deste negócio falido ou quase falido, então é preciso enfrentar tudo. Automaticamente num novo conceito como se fosse apagar toda a educação e ideologia que ele tinha ontem para agora fazer um processo de autogestão, democracia direta e sentir-se em um coletivo com responsabilidades de dirigir, produzir, comercializar, representar, se articular e negociar com bancos, empresas e ainda construir políticas públicas.

Mas temos também na economia solidaria outras iniciativas que surgem sem infraestrutura, sem equipamentos, sem capital de giro e sem mercado. Isso é um milagre dar certo? Sim é fruto de uma profunda persistência. Assim surgem muitas cooperativas de costureiras, de catadores e na área da agricultura familiar e agroecológica, artesãos, sociais e alimentação. Muitas destas iniciativas surgem e estão de forma ainda não regulamentadas, que definimos como grupos ou coletivos, essas trabalham na informalidade o retorno financeiro sempre é pouco, direitos quase não tem, vivem amanhã do que produzem hoje. Temos também as associações que muitas confundem suas práticas com as cooperativas, confundindo a função do associativismo com práticas de comercialização e estas estão especialmente na área rural e no artesanato. Outras iniciativas optaram por serem microempresas solidarias, geralmente por serem poucas pessoas e, sobretudo porque a legislação tributária atual beneficia esta forma de regulamentação.

Com esta diversidade compreendesse também organizações de redes que necessariamente não tem um produto ou serviço gerado, mas fomenta as várias formas de organização da economia social e solidária. 
Assim é a economia social e solidaria baseada em princípios claros e profundos que transformam as pessoas, no confronto direto por serem essencialmente coletivos, regidos pela democracia direta, pela divisão justa dos ganhos, pelos processos de autogestão e participação ativa de seus membros. Necessariamente isso constrói consciência. Não de forma impositiva, mas conquistada no dia a dia. Porem nem por isso todos tem esta pratica. Segundo Singer (2014), na $3^{\text {a }}$ conferência nacional de Economia Solidaria no Brasil, afirmou que a maioria dos empreendimentos de Economia solidaria que terminam são por problemas nas relações. Problemas na gestão. Assim como é profundamente realizador o trabalho coletivo é também profundamente difícil. Colocar-se aberto para mudar as práticas as atitudes, construir no dia a dia outro ser humano, é construir a Economia social e solidaria.

\section{Construção do conceito}

O cooperativismo e a Economia social e solidaria ambas buscam o trabalho coletivo para que se possa enfrentar o pior do capitalismo que é a desigualdade social. E essa desigualdade é gerada pela péssima distribuição da riqueza. A riqueza é gerada pela economia. A economia acontece com a produção de bens e serviços. Nesta estratégia não é possível transformar a economia se não tivermos cooperativas e iniciativas de economia solidaria fortes nos vários setores da Economia. Por isso que há um contraditório: enquanto alguns pensadores e ideólogos, sobretudo das organizações de apoio e das universidades concentrarem os conceitos e as elaborações, a grande maioria dos trabalhadores e trabalhadoras que estão na Economia solidaria e no cooperativismo não participam desta elaboração. Portanto continuam sendo trabalhadores alienados do processo de produção e do ponto vista da alienação política e social.

Se não influirmos nos processos de produção, comercialização e consumo não estamos construindo outra economia, estamos sim precarizando a vida dos trabalhadores e trabalhadoras que não querem um patrão, mas querem trabalhar coletivamente com dignidade, portanto com retorno econômico. Há um esforço, mas é profundamente necessário que as universidades e organizações de apoio contribuam e provoquem este encontro dos trabalhadores e trabalhadoras da Economia social e solidária.

\section{A política pública emancipa?}

A política pública, pode ser assistencialista ou emancipatória, por isso merece um destaque. Precisamos de políticas públicas de Estado, de políticas de governo e de Governos 
comprometidos com as causas sociais. É um tripé importante. Onde conseguimos juntar esse tripé temos um avanço significativo da Economia solidária, com leis, programas e ações que fortalecem de fato a construção de outra economia. Poderíamos destacar várias experiências de cidades, Estados e países de nossa América Latina, que tem passos importantes como leis nacionais de economia social e solidaria no Equador, leis atualizadas do cooperativismo inclusive permitindo filiais de cooperativas como é o caso do Uruguai, leis de compras públicas do cooperativismo e Economia solidária no Brasil. Decretos e leis de comercio Justo. Também programas pontuais de formação, apoios em infraestrutura, equipamentos e comercialização. Fortalecem esta forma de promovermos desenvolvimento. Porem quando os governos são de direita, essas leis não são aplicadas, os programas terminam, as prioridades são outras. Ter a consciência clara que o destino do dinheiro público necessita uma constante vigilância da sociedade sobre quem está nos governos, e se envolver nas decisões da política pública é hoje um tema colocado para garantir o presente e futuro da Economia solidaria. Manter a autonomia do movimento, é ter posições claras, bandeiras definidas, e saber onde queremos chegar. Definir uma plataforma de políticas públicas eleger representantes comprometidos com esta plataforma é um desfio colocado. As políticas públicas devem nos fortalecer pois o que mais queremos não é egoísta, é coletivo, é o Bem comum.

\section{Reais impactos da economia solidária na construção de outra economia}

O enfrentamento deste modelo econômico, deve ter por parte do sistema cooperativista autentico junto a outras formas de economia solidaria, sejam estas como associações, coletivos, grupos, microempresas solidarias, com todos os setores de organização social de raça e gênero nos mais variados setores da economia, seja em todas as áreas de atuação estarmos fortemente fortalecidos em redes, redes que gerem serviços, bens e produtos, isso que poderá fortalecer a integração entre os pequenos e iniciantes com os já estabilizados. Isso poderá dar impacto para outra economia, ou seja, é necessário que as artesãs se articulem para adquirir por melhores preços suas matérias primas, que as costureiras se articulem para a compra dos tecidos, que os agricultores se articulem em redes para a compra de sementes e insumos, que os catadores se articulem em redes para vender os resíduos com melhor valor, que as educadoras se articulem em rede para uma educação de impacto e assim por diante. Esse é um passo importante para que muitos empreendimentos saiam da situação de pobreza que vivem hoje. Muito pode ser enfrentado na articulação das redes que são fundamentais para fortalecer esta outra economia. Perguntamo-nos que outra economia isso fortalece? Os capitalistas também atuam em rede? As 
redes dos capitalistas fazem com que eles sejam mais ricos e concentrarem mais a renda gerada. As redes da Economia fazem com que esta riqueza venha para cá e fortaleça os coletivos e fortalece uma relação mais horizontal.

$\mathrm{E}$ as cadeias produtivas solidarias?

As cadeias são um processo vertical das redes, é juntar setores econômicos diferentes que estão dentro das redes. Dois exemplos importantes: A Justa Trama, junta 5 regiões do Brasil, 6 cooperativas e associações e dois coletivos envolve desde os agricultores que plantam o algodão orgânico, cooperativa de tecelagem que faz o fio e o tecido, cooperativa de costureiras e de calçado, cooperativa de artesanato para os adereços/ botões e coletivos para os brinquedos e todas com o algodão orgânico desde o plantio até a produção das roupas. Todo esse processo se completa com a comercialização. Nesta cadeia que articula todos os elos de produção todos ganham, pois não tem atravessador, todos os processos são feitos em cooperação por cooperativas e associações da economia social e solidaria. Neste sentido não estamos fazendo redes para comprar de uma empresa capitalista por melhores preços, e que de certa forma concentramos nossa compra em um a empresa que enriquece mais ainda, mas estamos com todos os processos de uma cadeia e, portanto, desde o primeiro ao último todos ganham de 50 a $100 \%$ acima do mercado se fizesse o mesmo produto. Neste exemplo em particular, além disso, estamos falando de algodão orgânico. Portanto enfrentando o sistema não só no processo, mas também nos insumos de agrotóxicos já que o algodão concentra $25 \%$ dos agrotóxicos do planeta. Estamos falando de um País, Brasil que tem o maior mercado consumidor de agrotóxicos e que os últimos estudos apontam segundo Stedile (2018), do MST (Movimento dos trabalhadores sem-terra) cada brasileiro consome em média 5 litros de agrotóxicos por ano.

E neste sentido podemos projetar cadeias curtas ou longas, locais ou de integração nacional ou mesmo binacional. Mas precisamos avançar na ousadia. Não é possível não integrar as artesãs que trabalham com lã com cooperativas que fazem a lavagem da lã e com os criadores de ovelhas. Integração entre os pescadores com o beneficiamento do couro do peixe e das escamas, além de cooperativas de alimentação. As várias iniciativas de alimentação que não integram com os agricultores que tem o trigo, o arroz, as farinhas, as frutas, os sucos. Integrar as cooperativas na área da construção com as cooperativas habitacionais.

Isso é urgente e profundamente necessário. São as cadeias de produção da economia solidaria que se entrelaçam, buscam seus elos para se fortalecer e serem correntes fortes que fazem o impacto nesta economia.

Neste sentido é profundamente urgente desenhar estratégias destas redes e cadeias e promover o encontro e o fortalecimento das mesmas. As cooperativas e outras formas de 
organização já existem e atuam de forma isolada, provavelmente haverá elos que precisem ser criados, mas é para isso que estamos refletindo. Essa estratégia deveria nos guiar nas próximas ações para fortalecer especialmente a América Latina. Essa estratégia é importante que tenham dois motores guias:

Desenvolver cadeias que tenham um recorte de preocupação com o meio ambiente. Que estejam acompanhadas de políticas públicas para que o Estado cumpra seu papel de governar para todos, colocando o ser humano em destaque e prioridade e portanto, promovendo uma economia sustentável. Promover políticas que fortalecem a Economia Social, solidaria e cooperativada é promover um desenvolvimento inclusivo, equilibrado no sentido da distribuição justa da renda, portanto da Justiça social.

Os trabalhadores e trabalhadoras das cooperativas, associações e coletivos da Economia solidaria devem ser os protagonistas, os estrategistas desta construção. Porque transforma vidas, transforma conceitos e transforma consciências. O coletivo nos transforma é essa é a essência do Cooperativismo, e as conquistas coletivas nos realizam como seres humanos, a alegria e felicidade que poderia ser de um é de muitos.

É possível construir outra economia, na qual a vida prevaleça sobre o trabalho, e o trabalho prevaleça sobre o capital.

\section{REFERÊNCIAS}

BRASIL. Lei n. 5.764, de 16 de dezembro de 1971. Define a Política Nacional de Cooperativismo, institui o regime jurídico das sociedades cooperativas, e dá outras providências. Diário Oficial [da] República Federativa do Brasil: Seção 1, Brasília DF, p. 10354.

SINGER, P. Economia e democracia. Trabalho apresentado ao $3^{\text {a }}$ Conferência Nacional de Economia Solidaria no Brasil. Brasília, 2014.

STEDILE, J. P. Golpe colocou Brasil na contramão do mundo na legislação ambiental. Disponível em: http://www.mst.org.br/2018/06/13/golpe-colocou-brasil-na-contramao-domundo-na-legislacao-ambiental.html. Acesso em: 22 nov. 2018. 